\title{
Android mobile application for wildfire reporting and monitoring
}

\author{
Rony Teguh" ${ }^{1}$, Fengky F. Adji ${ }^{2}$, Benius $^{3}$, Mohammad Nur Aulia ${ }^{4}$ \\ ${ }^{1}$ Department of Informatic Engineering, Faculty of Engineering, University of Palangka Raya, Indonesia \\ ${ }^{2}$ Department of Agro-Technology, Faculty of Agriculture, University of Palangka Raya, Indonesia \\ ${ }^{3}$ Department of Economic Development, Faculty of Economic and Bussiness, University of Palangka Raya, Indonesia \\ ${ }^{4}$ Regional Revenue Agency Province of Central Kalimantan, Indonesia
}

\begin{tabular}{l}
\hline \hline Article Info \\
\hline Article history: \\
Received Aug 30, 2021 \\
Revised Oct 29, 2021 \\
Accepted Nov 2, 2021
\end{tabular}

Keywords:

Android smartphone

Central Kalimantan

EXIF metadata

GNSS

Peat fires

\begin{abstract}
Peat fires cause major environmental problems in Central Kalimantan Province, Indonesia and threaten human health and effect the social-economic sector. The lack of peat fire detection systems is one factor that causing these reoccurring fires. Therefore, in this study, we develop an Android mobile platform application and a web-based application to support the citizenvolunteers who want to contribute wildfires reports, and the decision-makers who wish to collect, visualize, and evaluate these wildfires reports. In this paper, the global navigation satellite system (GNSS) and a global position system (GPS) sensor from a smartphone's camera, is a useful tool to show the potential fire and smoke's close-range location. The exchangeable image (EXIF) file image and GPS metadata captured by a mobile phone can store and supply raw observation to our devices and sent it to the data center through global internet communication. This work's results are the proposed application easy-to-use to monitoring potential peat fire by location and data activity. This paper focuses on developing an application for the mobile platform for peat fire reporting and a web-based application to collect peat fire location for decision-makers. Our main objective is to detect the potential and spread of fire in peatlands as early as possible by utilizing community reports using smartphones.
\end{abstract}

This is an open access article under the CC BY-SA license.

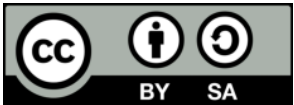

\section{Corresponding Author:}

Rony Teguh

Department of Informatics Engineering, Faculty of Engineering

University of Palangka Raya

Palangka Raya City, Central Kalimantan Province, Indonesia

Email: ronnyteguh@gmail.com

\section{INTRODUCTION}

Peat fires have caused environmental problems in Indonesia, especially in the province of Central Kalimantan. This problem also leads to significant economic losses, increased local poverty, widespread health problems, and biodiversity losses [1], [2]. Fires in the degraded peatland are difficult to extinguish and can burn for days or weeks. The smoke from peat fires produces gas and toxic when inhaled by human, disrupting the respiratory system [3], [4]. Therefore, it is crucial to detect and tackle the peat fires before the fires spread and become uncontrollable to minimize the disruptive effects. Monitoring system for peat fire is currently based on satellite [5]-[7] or using wireless sensor networks [8], [9]. Both technologies present serious drawbacks limiting their performances. The deployment of in-field wireless sensor networks and satellite sensors cannot provide sufficient accuracy when the area was covered with thick smoke and cloud. The sensors are available in smartphones such as ambient light, compass, accelerometers, global position 
system (GPS), and cameras (see Table 1) are often used by citizens to georeferenced and report visible peat fire in fact as they are using the camera smartphone. Also, geotagged and camera pose estimation using smartphones, and a global navigation satellite system (GNSS), are implemented in a few disaster cases. Nowadays, citizen science or collaboration between citizen and professional scientist are widely used in scientific research especially ecological and biodiversity research [10], [11]. The citizen mostly takes parts in data gathering, entering the data online into the centralized and relational. However, there are many biases and uncertainty associated with citizen project. Chen et al. [12] raised some challenges related to data quality and legal issues of using volunteered geographic information in (VGI) for disaster management. The latest research provided by Kirchhoff et al. [13] mentioned that there are biases in the spatial and temporal sampling when the citizen uploading the photographs of fire location. To improve the quality of the science citizen data, few researchers suggested to combine the data with other data source provide guidebooks and training on how to use the equipment and assess the accuracy and quality of the data.

This paper focuses on developing an application for the mobile platform for peat fire reporting and a web-based application to collect peat fire location for decision-makers. Our main objective is to detect the potential and spread of fire in peatlands as early as possible by utilizing community reports using smartphones. The potential for small fires on peatlands is challenging to detect using satellite technology such as moderate resolution imaging spectroradiometer (MODIS). The occurrence of clouds, haze, and reflected heat from the roof might deliver false alarm in the fire detection. The mobile application we proposed in this paper is useful for validating the hotspot captured by the satellite. The object image data ability to store use a smartphone as a mobile mapping [14], [15] to geotag close-range objects employing photograph techniques to overcome the accuracy of navigation sensors and supply raw observation to our devices and send to the data center by global communication data.

The GNSS positioning system can supply reliable information for performing close-range objects of an ignition and peat fire. Our systems present a whole new method in identifying and detecting peat fire. By exploiting the smartphone sensors, we introduce new methods for the concerned citizens such as firefighting, volunteers, and local people to effortlessly contribute the position of fire information at a close-range only using their smartphones. People who care about the potential fire can directly obtain the data if there is a fire near their location. All data collect and display to Google Map services includes data geographical, altitude, address, fire reporting status, and tracking of fire of position. The implementation of our software can fill the gap between the high-quality data and low-availability measurements from wireless sensor networks also high-availability data and low-quality measurements from satellite sensors.

\section{RELATED WORKS}

There is a growing body of work based on data activity and geotagged photos. Park et al. [16], the author has shown that the additional GPS information helps visual recognition for geotagged photos by providing location context. Masiero et al. [17] the author work using the smartphone's positioning in the built environment was cellular coverage available in precise point position (PPP). The other works [18], development a GPS data only identifies the camera location, leaving the viewing direction uncertain. To produce more precise location information, i.e. the viewing direction for geotagged photos, we utilize both google street view and google earth satellite images.

Lemieux [19] studies employing geotagged photographs use publically available images found on photo sharing sites. This paper argues geotagged photos are a novel way to record such data quickly and efficiently. Moreover, the methodology is suitable for a variety of criminological inquiries and settings. Spatial and temporal analyses of human movements are one of the most common ways geotagged photos have been used as a secondary data source. Liu et al. [20] proposes a method to build an index based on multiple classification result, which can divide the data set multiple times and distribute labels to the data to build index according to the estimated probability of classification results in order to accomplish the identification of users' important location and daily behaviors.

Dabove et al. [21] has explained that the GNSS pseudo-range and carrier-phase measurements mobile devices as smartphones and tablets with an Android operating system has transformed the concept of accurate positioning with mobile devices. Liu et al. [22] has showed, a novel computational method of lowcost forest inventory using GNSS signals in a crowdsourcing approach. By this method, to predicted forest attributes, including tree height, diameter at breast height, basal area, stem volume, and above-ground biomass, in boreal forest conditions we should extracted the data from widely available GNSS devices by using statistical analysis of GNNS signals.

Fan et al. [23] According to that statement, this paper designs a sensor box for personal smartphones could be integrates with various types of sensors and makes it compact and easy to bind the two to each other. Kafee et al. [24] has showed location-based services (LBS) refer to services that account for the realtime, geographic positions of a person or mobile object, as determined by GNSS. Kumar et al. [25] proposed 
article verifies the metadata associated with image and track the individual country, city, route and street based on the GPS altitude, GPS latitude, GPS longitude and GPS position.

\section{RESEARCH METHOD}

GNSS position technique could be measured the distances between the user receiver and the position of at least four satellites of the same constellation. The GNSS satellite calculates the distance between receiver and satellite is equal to the signal propagation time if the transmitter and receiver clock are perfectly synchronized. The smartphones receive the signals of fully operational systems GPS (USA), GLONASS (Russia), and those still developed, such as Chinese BeiDou and European Galileo. Therefore, potential failures in accuracy achievement and can cause errors such as navigating near an edge of a fire line, firefighter, or other activities in the location-based.

The smartphone's positioning in the built environment was cellular coverage available in precise point position (PPP). GNSS devices can correctly position within $5 \mathrm{~cm}$ of line of sight (LOS) and less than $0.5 \mathrm{~m}$. non-line of sight (NLOS) propagation can be done with high accuracy due to cellular tower trilateration, map-matching, and the other methods integrated into phones or apps that improve or substitute for GNSS-based positioning. The proposed system enables multiuser to report peat fire activities directly from the location of the fire. Figure 1 shows how the system works, where the observation data is sent to the server and validated in the web-based system.

The GPS mobile application receives timing and range data from different satellites and later uses these to establish its location on the Earth's surface. The firefighter use of mobile GNSS receivers has been useful in wildfire and determine fire for maintaining reference position, tracking, and marking waypoints of inhibiting or other hazards, relaying coordinates of spot fires, and delineating burn perimeters to confirm area burned. The weakness in using the GNSS position method is the weather and forest environment factors. These two factors extremely influence the accuracy and precision in determining position and distance measurement of an object. The total and geometry calculation of satellites observable to a GNSS receiver at any point in time also affects the accuracy of coordinate readings recorded by the device.

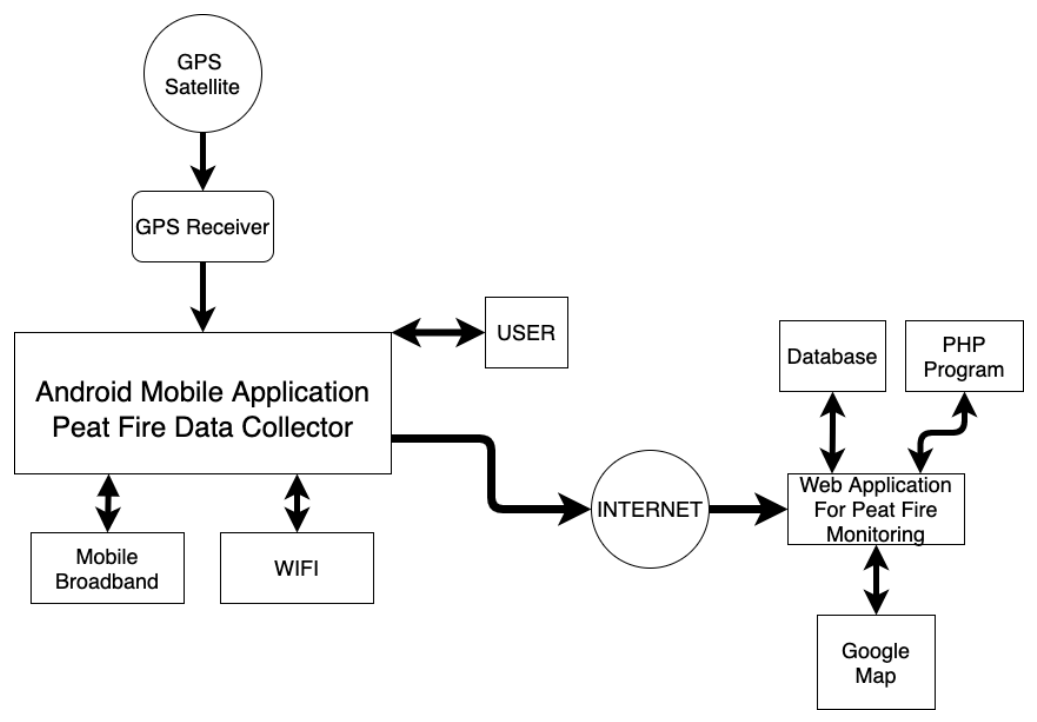

Figure 1. Overview system of the architecture for peat fires monitoring

\subsection{The smartphone android system}

Smartphone now has an internal GNSS receiver, and it has been feasible to have GNSS raw data by the mobile platform. The capability to save and supply raw observations directly from the Android operating system application programming interface (API) makes smartphones exciting tools for positioning in a whole series of fields that do not require a geodetic receiver's ability. The smartphone obtains the location and elevation to determine the device's positioning accuracy from GNSS satellite.

Nevertheless, peat fire management activities often occur in areas where cellular coverage is inadequate. The stability and coverage of mobile connectivity are primarily useful in the forestry and peat 
fire activities to occur in proximity to the forest environment; it is the citizen interface. Even in these areas, it is common for mobile connectivity to be lost or possible to relay location coordinates to others via mobile data transfer using conventional cellular overloaded during large fires and other natural disasters. Table 1 shows the specification of smartphone devices used in the implementation for peat fire monitoring.

Table 1. The smartphone android system specification

\begin{tabular}{cl}
\hline Receiver & \\
\hline Constellation & GPS, BeiDou, GLONASS \\
Detail OS & Funtouch OS 4.5 \\
Network & 2G GSM, 3G WCDMA, 4G FDD-LTE, 4G TDD-LTE \\
Sensor & Fingerprint, accelerometer, ambient light sensor, proximity sensor, e-compass, gyroscope \\
\hline
\end{tabular}

\subsection{Development mobile app for reporting peat fires}

In this paper, we design and develop a mobile app for reporting peat fires by citizen observation. The mobile application allows citizens to capture the object of fire, geo-location, and report. Figure 2 shows the visual map and exchangeable image file (EXIF) metadata used to take an image from the mobile application. The citizen should enable permission to use the GPS device, camera, and internet connection. Firstly, the smartphone receives the GNSS data through the satellite signal, and then the position of the mobile app will be shown on the map.

When a citizen takes a picture of peat fires, they check the map's horizontal accuracy shown on the smartphone screen. The photo captured by the citizen smartphone afterward delivers directly to the cloud server using global internet communication. If the internet connection is not available at the time of taking the photo the application can store image data and coordinates into a local smartphone memory, then send it to the server after an internet connection is obtained. The first activity is to get an accurate position through the propagation signals from more than four satellite the same GNSS when the mobile application runs. The GPS sensors determine the GNSS satellite's position on smartphone devices to acquire earth coordinates and embedded into the file as metadata images. Furthermore, the application activates the front camera of the smartphone to take the image. The camera automatically creates EXIF data when the image is taken.

The photo's EXIF data is displayed in a friendly, readable format with the following data: date and time taken, image name, size, and resolution, camera name, aperture, exposure time, focal length, and the camera's sensor (ISO), location data, latitude/longitude, and map. Figure 2 also shows that citizen could see the information of the fire locations on the smartphone. On the mobile app, the users can send and receive the description of the EXIF photo metadata of the objects in the map. The citizen can create and take a photo with a single or multiple images of various directions at a similar GPS location point in a fire event. The mobile application could act as an early warning system that provided information to prevent peatland fire spread.

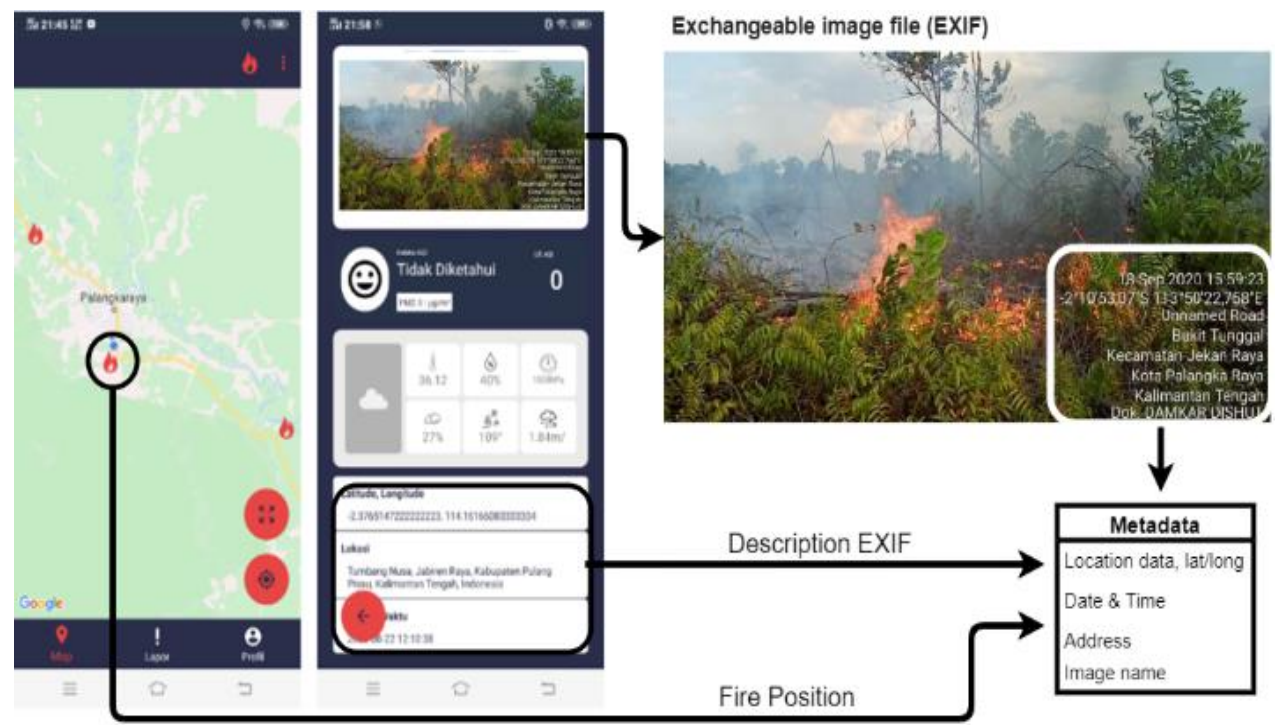

Figure 2. The mobile mapping and EXIF photo metadata 


\subsection{Web application reporting for peat fire monitoring}

The web-based application is used to visualize the spatiotemporal status of peat fire taken from a citizen smartphone. The EXIF photo and its other information are simultaneously received by the server and recorded into the database. In this paper, the web-based application has a map displayed on the web. The decision-makers, fire authorities, firefighters, and citizens can use this map to see the peat fires' location and characteristics. There are two web application features: the peat fire's visualization and fire and smoke identification (Figure 3). Our application also integrates with Google Map application programming interface, query location, direction, street view, and road route (Figure 4). Once a citizen reports a possible fire in a region, the information is delivered to the data center. The web system administrator verified EXIF metadata and images to confirm whether the fire alert report is correct and precise. The next step is for firefighters to receive notification from the web-based system. The notification consists of information of an image, hotspot position, and fire level. The application is also able to extract all data sent by the user's smartphone. These data can be used for further analysis using different applications such as geographic information systems (GIS).
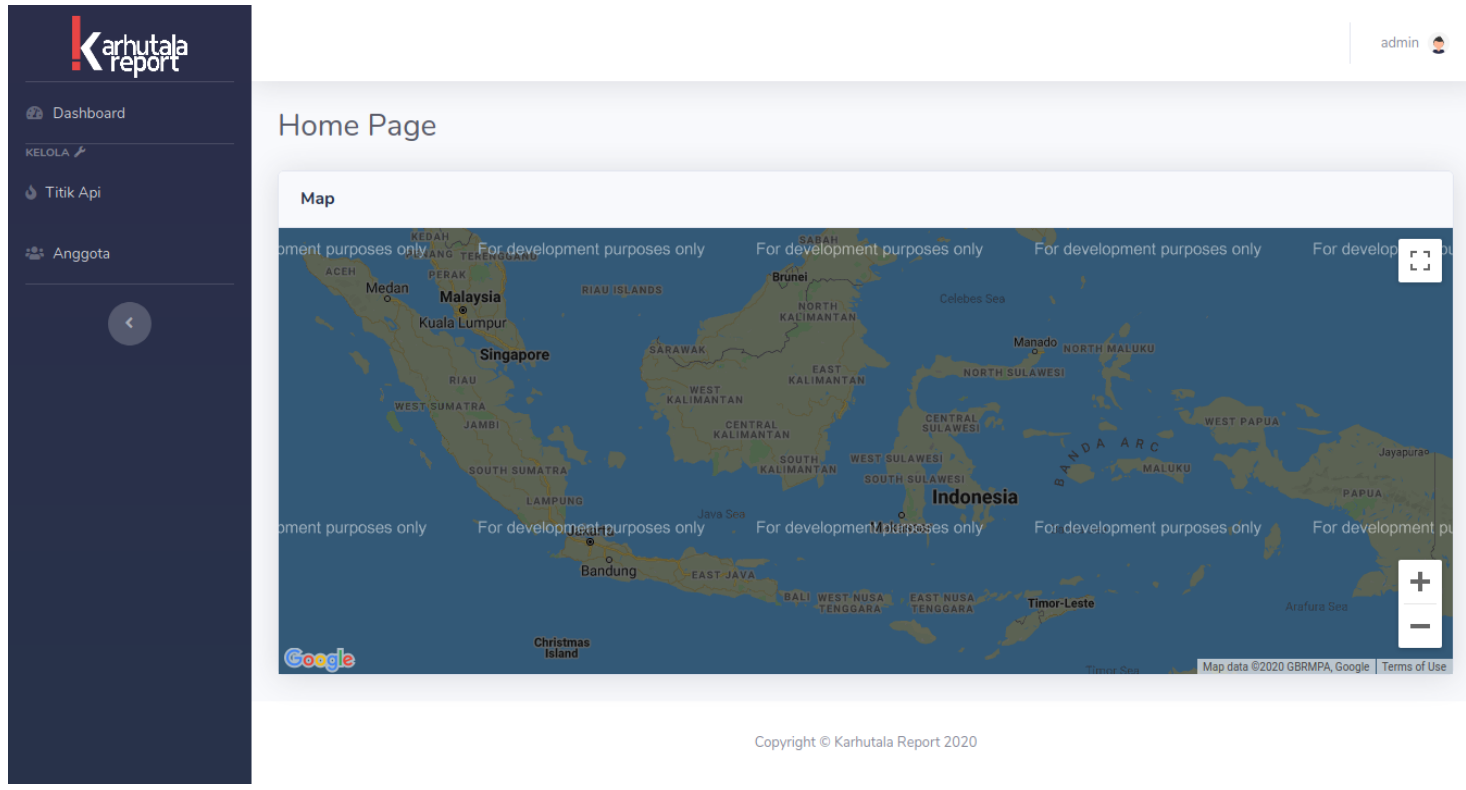

Figure 3. The visual hotspot data for reporting peat fire monitoring

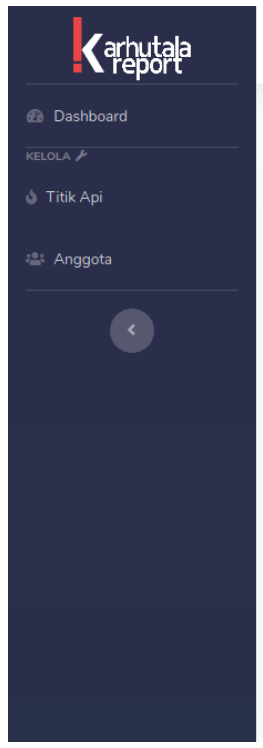

Kelola Titik Api

Daftar Titik Api Baru

Show $10 \leqslant$ entries

No $\uparrow$ Latitude (Lintang)

Search

\begin{tabular}{|l|l|l|l|}
\hline 1 & -2.2167506111111113 & 113.90582275 & JL. Cik Ditiro, No. 6, Palangkaraya, Central Kalimantar
\end{tabular} Menteng, Jekan Raya, Palangka Raya City, Central Kalimantan 74874, Indonesia

\begin{tabular}{|l|l|l|l|}
\hline 2 & -2.2054033333333334 & 113.88548277777778 & II. Bukit Indah III No.10, Palangka, Kec. Jekan Raya.
\end{tabular} Kota Palangka Raya, Kalimantan Tengah 74874 . Indonesia

\begin{tabular}{|l|l|l|l|}
\hline 3 & -2.2167513333333333 & 113.90583036111111 & J. Cik Ditiro No.57, Menteng, Kec. Jekan Raya, Kota
\end{tabular} Palangka Raya, Kalimantan Tengah 74874, Indonesia

Figure 4. The information of data record fire location and address 


\section{RESULTS AND DISCUSSION}

In this paper, we tested our application using real peat fire events. We used different objects in the peat environment like a forest, non-forest, and farm. The image metadata was taken from 23 July-06 September 2020, where citizens are reporting the location of peat fires using their smartphone. The citizen uses the mobile application and takes an image using the mobile application and send it to the database server through internet communication. In the web-based application, the fire authority checks the correctness of the information and then validate it. Once it is validated, the fire authority sends the information of fire position, address, and status of the environment such as peat, forest, and farm to the firefighters on the field.

\subsection{The citizen data collect and reporting}

In disaster management, citizen science refers to a data collection technique that encourages the public to voluntarily provide answers to questions or content for usage through a global transmission system like a smartphone. The idea of first-hand reporting, mainly in the form of visual documentation through smartphones, has emerged as the prime need for responding to peat fire disasters. Our proposed mobile app allows data collection from the disaster-struck areas in offline mode using GPS, and some other sensors also continue to function even without network access. The mobile app helps firefighters communicate by enhancing upstream and downstream coordination during fire disasters. The app can act as an early warning system with detailed hazard maps with fire images and locations.

These mobile technologies connect the citizen to real-time disaster information at one go. Figure 5 shows the citizen or firefighter patrol's workflow in capturing a peat fire image using the smartphone's camera. When the smartphone is used, the GPS sensor is enabled. The photo obtains automatics geotagged based on the best calculation of the GNSS position. A citizen reporting a fire object can directly send the EXIF photo to the database cloud through the internet. The web-based application will receive the peat fire information; the validation process is conducted before the fire information is visualized on the map. The coordinates are shared with the firefighter. The citizen and firefighters accept the fire's current actual position from their smartphone devices as fire alerting.

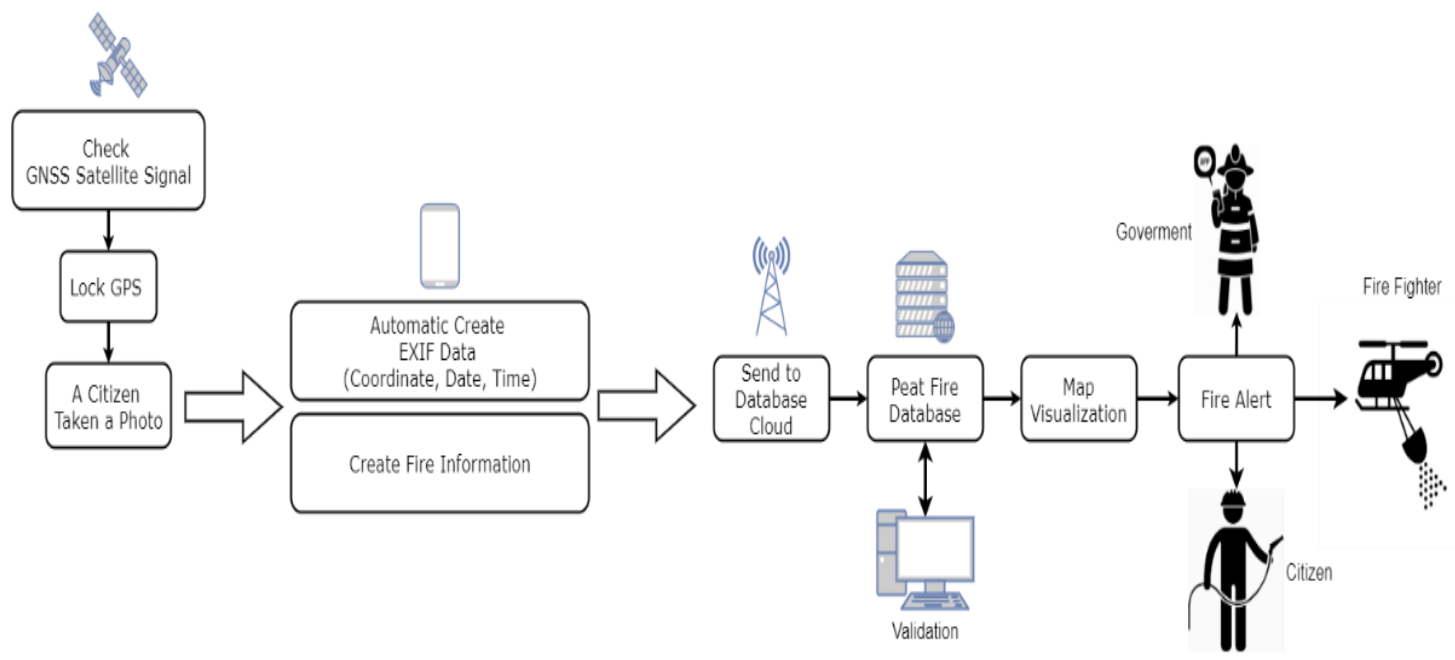

Figure 5. The flowchart citizen reporting using smartphone

Figure 6 shows the user interface of the mobile application. The citizen should install the mobile application into its smartphone with an android operation system. In the application, the citizen needs to register first using email and mobile number and then enable permission for GPS device, camera, and internet connection. The mobile app reads the GPS data from the GNSS satellite signal and shows the user's position on the map. Before taking the picture, the citizen must check the map's horizontal accuracy on the smartphone. The data then deliver to the server using global internet communication. The image could be saved into memory as EXIF metadata. The firefighters and citizens can provide a text description of the real situation on the fire location. The description consists of soil types, water sources, and types of burn materials such as grass, dry wood, and land types such as agricultural land, forest, non-forest, or oil palm plantations. Anyone can collect, process, store and share relevant disaster-related information such as photos and messages, which can be coupled with satellite data. 

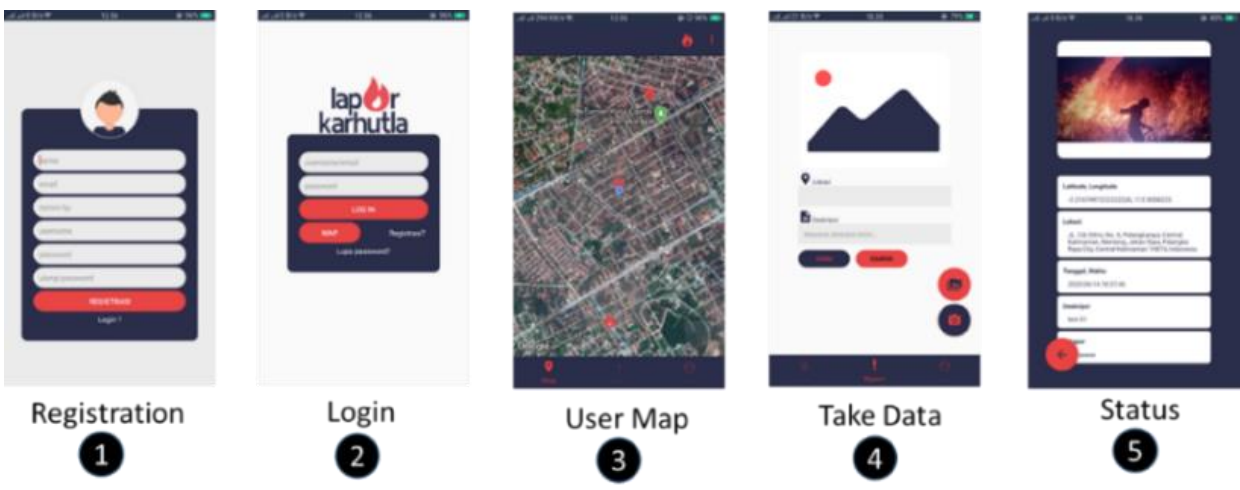

Figure 6. The flow for citizen collects data and reporting using smartphone

\subsection{The fire fighter identification and monitoring}

This paper shows that firefighters can test and use the web-based application to analyze data and visualization the status of the spatiotemporal location of a peat fire from citizen's report. The EXIF image and its information are simultaneously forwarded to the application through the communication channel. The image and metadata location will be extracted and recorded to the database. Figure 7 shows the interface of a web-based application for monitoring and identification of the fire's locations. There are two functions in this web-based application: visualization of fire and smoke and identification of fire and smoke. The fire information from the map can show fire's real condition by one day, one week, and one month. It has detailed information of the reported fire image, marked waypoint, spot fire coordinates, and delineating burn perimeters. Every information metadata has a GPS location of the image, capturing date and time. The original image is saved into the database using a Joint photographic experts group (JPG) format. Table 2 presents the fire information identified based on the image. This information is GPS coordinates, date, time, and several additional data such as soil type, water source, fuel type, and land status as described by citizens.

Figure 7 shows the firefighter could identify the fire's location from the validated image descriptions and additional information. The firefighters can estimate the distance and road to the location, soil type, water source, and land status. During the dry season, groundwater levels are of key importance in controlling fires on peat. The citizen and firefighter describe the status of the source of water as reference data at each different location. Table 2 presents a database of the citizen's reports during fires in the peatland. The metadata consists of information on where, when, how, and the situation during the fires. This information can be used as the initial basis for fire prevention and extinguishing strategies.

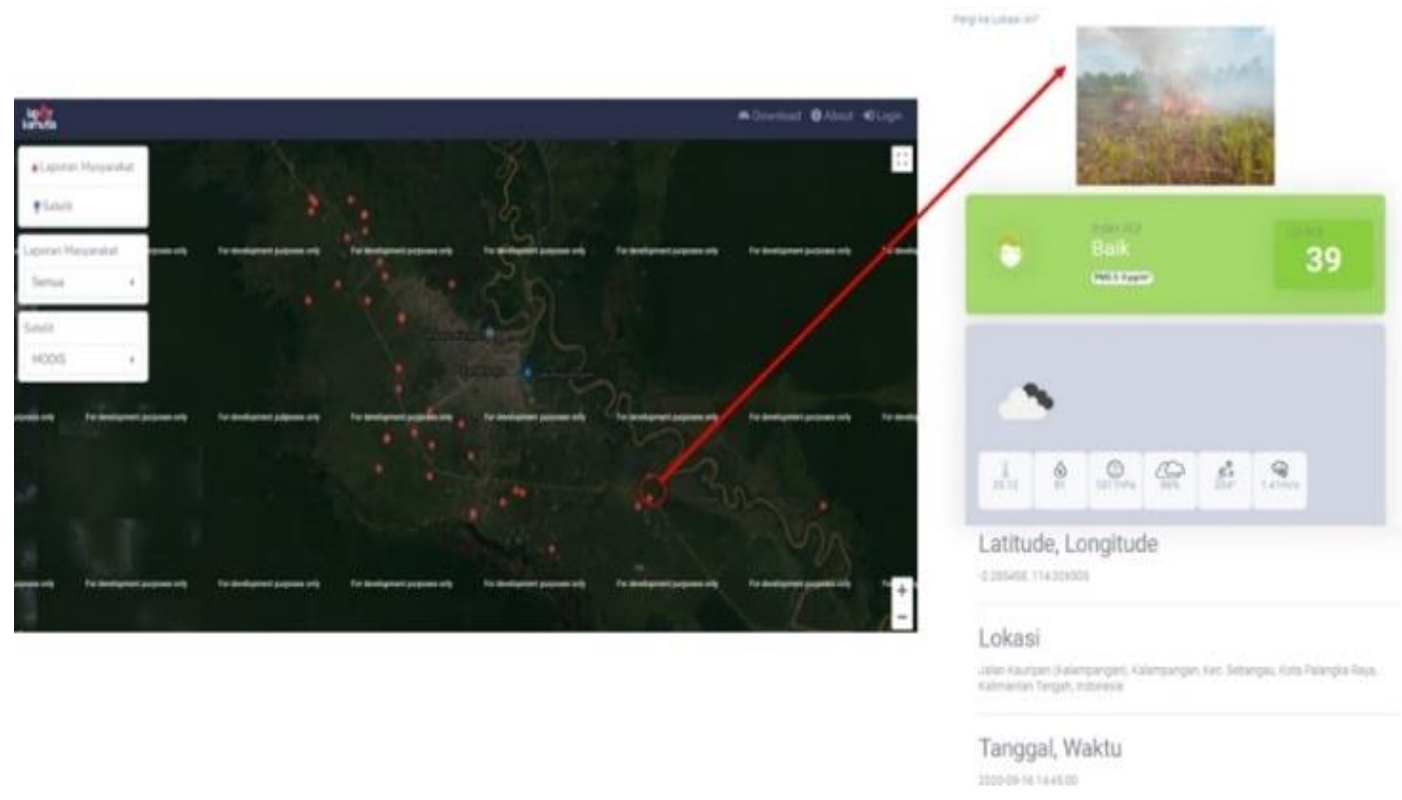

Figure 7. The detail visualization information of reported peat fire geotag-position 
Table 2. The result of peat fire attribute data reporting

\begin{tabular}{|c|c|c|c|c|c|c|c|}
\hline Latitude & Longitude & Date & Time & Soil Type & Water Source & Fuel Type & Status \\
\hline-2.31228 & 113.9618 & $23-07-20$ & $2: 01: 31 \mathrm{PM}$ & Peat & Far & Thatch & Agriculture \\
\hline-2.21685 & 113.8602 & $24-07-20$ & $3: 42: 48$ PM & Peat & Near & Thatch & Agriculture \\
\hline-2.12954 & 113.8048 & $26-07-20$ & 1:53:01 PM & Peat & Near & Bush & Agriculture \\
\hline-2.18144 & 113.8004 & $28-07-20$ & 2:10:00 PM & Peat & Near & Bush & Agriculture \\
\hline-2.37651 & 114.1617 & $22-08-20$ & 12:10:38 PM & Peat & Near & Bush & Agriculture \\
\hline-2.13443 & 113.8022 & $24-08-20$ & 1:48:23 PM & Peat & Near & Bush & Oil Farm \\
\hline-2.29444 & 113.9097 & $24-08-20$ & 3:47:50 PM & Mineral & Near & Bush & Agriculture \\
\hline-2.16056 & 113.8482 & $27-08-20$ & $6: 25: 01 \mathrm{PM}$ & Peat & Far & Bush & Agriculture \\
\hline-2.18981 & 113.8625 & $30-08-20$ & 12:40:00 PM & Peat & Near & Bush & Agriculture \\
\hline-2.27377 & 113.8809 & $31-08-20$ & 1:37:29 PM & Peat & Near & Bush & Agriculture \\
\hline
\end{tabular}

\subsection{The peat fire tracking and measurement}

In this study, our method can help firefighters to track and evaluation the waypoint fire position by citizen reports. Using the information provided on the web application, firefighters can get information regarding roads, settlements, source of water sources, and arrival time into the location of fires. Figure 8 shows the tracing of the fire location of citizen reported fires during fire events. The firefighter patrol's initial position is the blue icon, while the fire's position is the red icon. The emergency response time of the firefighter determines the speed to stop the fire in the location. Therefore, the citizens' participation in identifying and monitoring nearby fires could help firefighters minimize the spread of fires on peat. The tracking position could help the firefighter measure the distance from the road to the fire source, including measuring the distance source of water and settlement areas to the source of the fire.

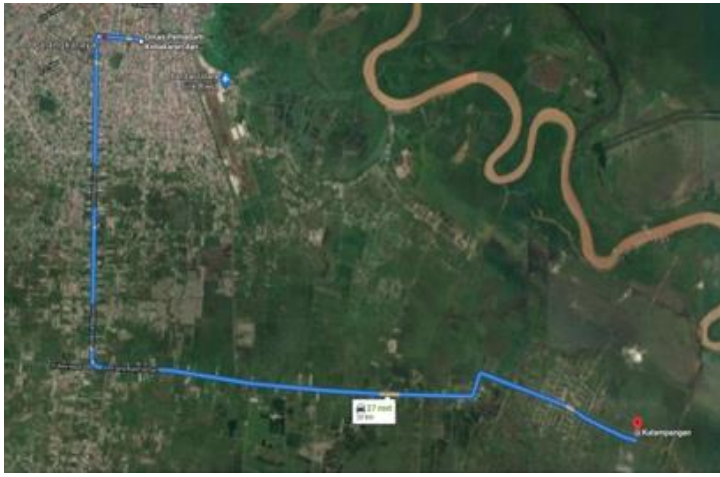

(a)

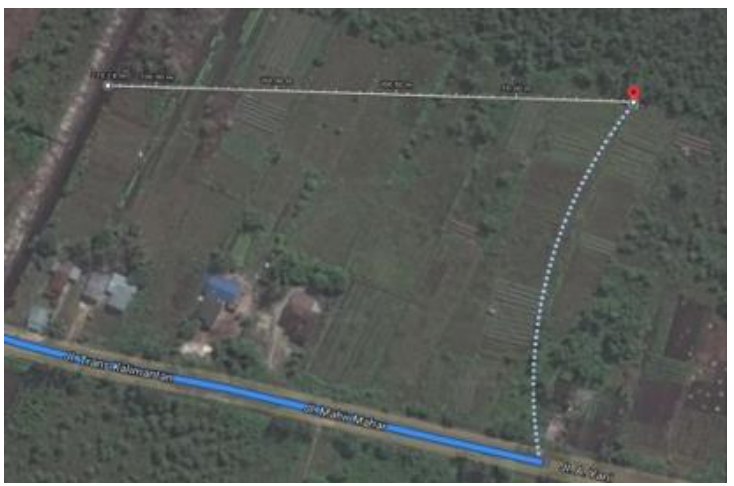

(c)

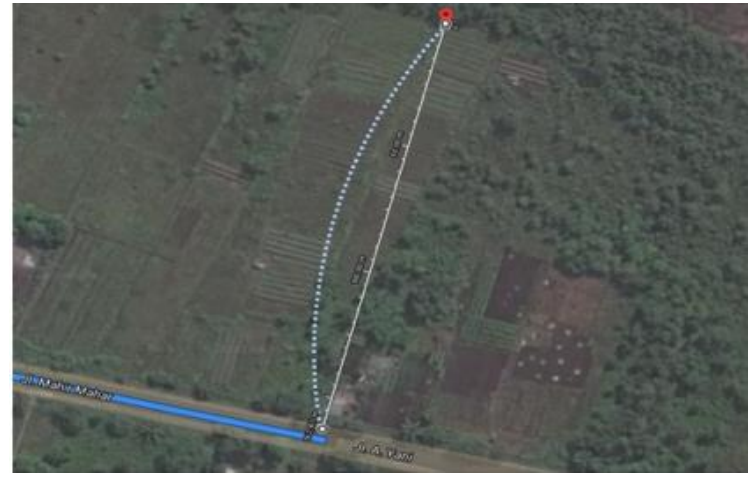

(b)

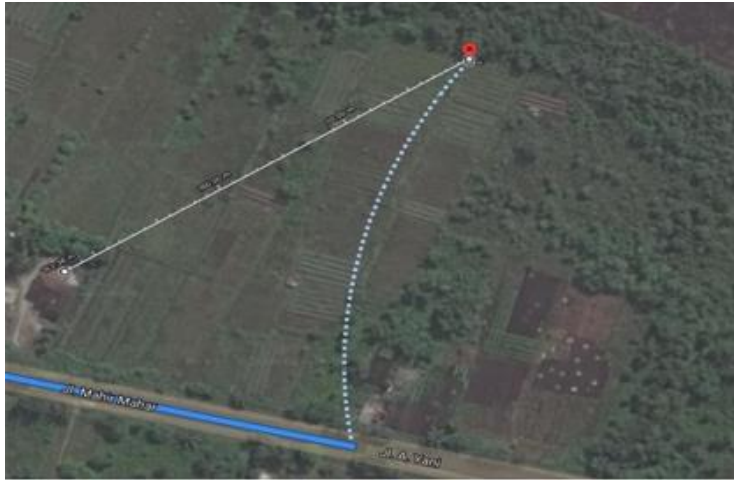

(d)

Figure 8. These figures are; (a) tracking fire from fire fighter (blue icon) to fire location (red icon),

(b) distance from road to fire location, (c) distance from source of water, (d) distance from settlement area

\section{CONCLUSION}

This paper proposes a system for reporting and detecting peat and forest fire with GNSS. Where is a mobile-based application using GNSS was built to calculate the user's location when taken the peat fire image and GPS metadata. The location and metadata are sent to the server using global communication 
systems. The system also has a web-based application that shows the location, image, and condition of the identity of fire's image. We test our system for the citizen uses the mobile application and takes an image using the mobile application and send it to the database server through internet communication. In the webbased application, the fire authority checks the correctness of the information and then validate it. Once it is validated, the fire authority sends the information of fire position, address, and status of the environment such as peat, forest, and farm to the firefighters on the field.

In this study, our method can help firefighters to tracking and evaluation the waypoint fire position by citizen reports. Using the information provided on the web application, firefighters can get information regarding roads, settlements, source of water sources, and arrival time into the location of fires. The combination of peat fire science and the proposed system can enhance the existing fire monitoring system and minimize peat fire's potential spread. Our systems present a whole successful in identifying and detecting peat fire. By exploiting the smartphone sensors, we introduce new methods for the concerned citizens such as firefighting, volunteers, and local people to effortlessly contribute the position of fire information at a close-range only using their smartphones.

\section{REFERENCES}

[1] R. Betha, M. Pradani, P. Lestari, U. M. Joshi, J. S. Reid and R. Balasubramanian, "Chemical speciation of trace metals emitted from Indonesian peat fires for health risk assessment," Atmospheric Research, vol. 122, pp. 571578, October 1994, doi: 10.1016/j.atmosres.2012.05.024

[2] G. J. Williamson, D. M. J. S. Bowman, O. F. Price, S. B. Henderson and F. H. Johnston, "A transdisciplinary approach to understanding the health effects of wildfire and prescribed fire smoke regimes," Environmental Research Letters, vol. 11, no. 12, doi: 10.1088/1748-9326/11/12/125009.

[3] F. Caamano-Isorna, A. Figueiras, I. Sastre, A. Montes-Martínez, M. Taracido and M. Pĩeiro-Lamas, "Respiratory and mental health effects of wildfires: An ecological study in Galician municipalities (north-west Spain)," Environmental Health: A Global Access Science Source, vol. 10, no. 1, pp. 1-9, doi: 10.1186/1476-069X-10-48.

[4] C. E. Reid, E. M. Considine, G. L. Watson, D. Telesca, G. G. Pfister and M. Jerrett, "Associations between respiratory health and ozone and fine particulate matter during a wildfire event," Environment International, vol. 129, pp. 291-298, doi: 10.1016/j.envint.2019.04.033.

[5] E. C. Atwood, S. Englhart, E. Lorenz, W. Halle, W. Wiedemann and F. Siegert, "Detection and characterization of low temperature peat fires during the 2015 fire catastrophe in Indonesia using a new high-sensitivity fire monitoring satellite sensor (FireBird)," PLoS ONE, vol. 11, no. 8, pp. 1-24, doi: 10.1371/journal.pone.0159410.

[6] C. D. Elvidge et al., "Long-wave infrared identification of smoldering peat fires in Indonesia with nighttime Landsat data," Environmental Research Letters, vol. 10, no. 6, doi: 10.1088/1748-9326/10/6/065002.

[7] F. Siegert, B. Zhukov, D. Oertel, S. Limin, S. E. Page and J. O. Rieley, "Peat fires detected by the BIRD satellite," International Journal of Remote Sensing, vol. 25, no. 16, pp. 3221-3230, doi: 10.1080/01431160310001642377.

[8] J. Lloret, M. Garcia, D. Bri and S. Sendra, "A Wireless Sensor Network Deployment for Rural and Forest Fire Detection and Verification," Sensors (Basel), vol. 9, no. 11, pp. 8722-8747, 2009, doi: 10.3390/s91108722.

[9] A. Molina-Pico, D. Cuesta-Frau, A. Araujo, J. Alejandre and A. Rozas "Forest Monitoring and Wildland Early Fire Detection by a Hierarchical Wireless Sensor Network," Journal of Sensors, vol. 2016, 2016, doi: $10.1155 / 2016 / 8325845$.

[10] J. L. Dickinson, B. Zuckerberg and D. N. Bonter, "Citizen science as an ecological research tool: challenges and benefits," Annual review of ecology, evolution, and systematics, vol. 41, pp. 149-172, doi: 10.1146/annurevecolsys-102209-144636.

[11] M. Haklay, "Citizen science and volunteered geographic information: Overview and typology of participation. Crowdsourcing Geographic Knowledge”, pp. 105-122, 2013, doi: 10.1007/978-94-007-4587-2_7.

[12] H. Chen, W. C. Zhang, C. Deng, N. Nie and L. Yi, "Volunteered Geographic Information for Disaster Management with Application to Earthquake Disaster Databank \& Sharing Platform". In IOP Conference Series: Earth and Environmental Science, vol. 57, no. 1, pp. 1-9, 2017, doi: 10.1088/1755-1315/57/1/012015.

[13] C. Kirchhoff et al., "Rapidly mapping fire effects on biodiversity at a large-scale using citizen science," Science of The Total Environment, vol. 755, 2021, doi: 10.1016/j.scitotenv.2020.142348

[14] A. Masiero, F. Fissore, F. Pirotti, A. Guarnieri and A. Vettore, "Toward the use of smartphones for mobile mapping," Geo-Spatial Information Science, vol. 19, no. 3, pp. 210-221, doi: 10.1080/10095020.2016.1234684.

[15] M. M. Nowak, K. Dziób, Ł. Ludwisiak and J. Chmiel, "Mobile GIS applications for environmental field surveys: A state of the art". Global Ecology and Conservation, vol. 23, 2020, doi: 10.1016/j.gecco.2020e01089.

[16] M. Park, J. Luo, R. T. Collins and Y. Liu, "Estimating the camera direction of a geotagged image using reference images". Pattern Recognition, vol. 47, no. 9, pp. 2880-2893, doi: 10.1016/j.patcog.2014.03.002.

[17] S. Choy, S. Bisnath and C. Rizos, "Uncovering common misconceptions in GNSS Precise Point Positioning and its future prospect," GPS Solutions, vol. 21, pp. 13-22, doi: 10.1007/s10291-016-0545-x.

[18] M. Park, J. Luo, R. T. Collins and Y. Liu, "Beyond GPS: Determining the camera viewing direction of a geotagged image," In Proceedings of the 18th ACM international conference on Multimedia, pp. 631-634, 2020, doi: $10.1145 / 1873951.1874038$. 
[19] A. M. Lemieux, "Geotagged photos: A useful tool for criminological research?," Crime Science, vol. 4, no.3, pp. 111, doi: 10.1186/s40163-015-0017-6.

[20] Guo-qi Liu, Yi-jia Zhang, Ying-mao Fu and Ying Liu, "Behavior identification based on geotagged photo data set," The Scientific World Journal, vol. 2014,2014, doi: 10.1155/2014/616030.

[21] P. Dabove, V. Di Pietra and M. Piras, "GNSS Positioning Using Mobile Devices with the Android Operating System”. ISPRS International Journal of Geo-Information, vol. 9, no. 4, pp. 220, 2020, doi: 10.3390/ijgi9040220.

[22] J. Liu et al., "A Novel GNSS Technique for Predicting Boreal Forest Attributes at Low Cost," in IEEE Transactions on Geoscience and Remote Sensing, vol. 55, no. 9, pp. 4855-4867, Sept. 2017, doi: 10.1109/TGRS.2017.2650944.

[23] G. Fan, Y. Dong, D. Chen and F. Chen, "New Method for Forest Resource Data Collection Based on Smartphone Fusion with Multiple Sensors," Mob. Inf. Syst., vol. 2020, 2020, doi: 10.1155/2020/5736978.

[24] R. F. Keefe, A. M. Wempe, R. M. Becker, E. G. Zimbelman, E. S. Nagler, S. L. Gilbert and C. C. Caudill, "Positioning methods and the use of location and activity data in forests," Forests, vol. 10, no. 5, pp. 458, doi: 10.3390/f10050458.

[25] P. R. Kumar, C. Srikanth and K. L. Sailaja, "Location Identification of the Individual based on Image Metadata," Procedia Computer Science, vol. 85, pp. 451-45, doi: 10.1016/j.procs.2016.05.191.

\section{BIOGRAPHIES OF AUTHORS}
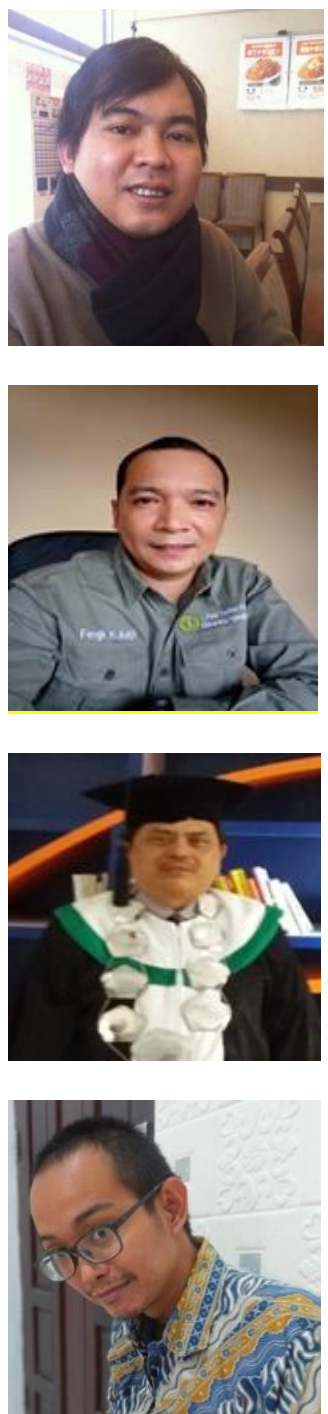

Rony Teguh received the M.Eng degree in Information Technology from the Gadjah Mada University, Indonesia, in 2011 and 2014, respectively. He is currently pursuing the Ph.D. degree in system science and informatics from the Graduate School of Information Science and Technology, Hokkaido University. His current research interests include wireless networks and data science. He have some collaborations with other (institution): BRGM, CIFOR, USAID, ACIAR, JICA, Hokkaido University, Melboune University, Michigan State University.

Fengky F. Adji took doctoral in Hokkaido University. His research interest is carbon flux and dissolved carbon in tropical peatlands, especially in burnt area and natural area. He has an experience in $\mathrm{CO}_{2}, \mathrm{CH}_{4}$, and $\mathrm{N}_{2} \mathrm{O}$ measurement by using chamber method and also have some collaborations with other (institution): BRGM, CIFOR, USAID, ACIAR, JICA, Kyoto University, Hokkaido University, fair venture worldwide and local government.

Benius received the M.Sc. degree in Management from the University of Jayabaya, Indonesia in 1999 and 2003, respectively, where he is currently pursuing the Ph.D. degree in Administration Bussiness from the Trinity College Manila. His research focus in citizen science and Bussiness administration modelling.

Mohammad Nur Aulia graduated from Institut Teknologi Pembangunan Surabaya, His research interest for development application e-Govement. 